\title{
Relapses in Leprosy
}

With Special Reference to the probable existence of a Neurotropic Virus form of Mycobacterium Leprae.

\author{
G. R. RAO.
}

\section{INTRODUCTION.}

\section{A} PERUSAL of the literature on leprosy reveals a remarkable paucity of papers dealing with relapses in leprosy. This is probably because the question of cure of the first attack itself is as yet unanswered. Leaving aside the early or moderately advanced neural cases, in whom any relapse is easy to detect, and the cutaneous cases that have been once rendered completely bacteriologically negative by adequate treatment but have relapsed, in which case also, it is easy to detect relapses by ordinary clinical and bacteriological examinations; we have to consider the probability of relapses in very advanced neural cases with disabling deformities and other trophic lesions.

Prior to the International Conference on Leprosy held at Manila in January 1931, it was widely believed that when disabling deformities had set in and there were no other neural or cutaneous signs to testify to the activity of the disease, leprosy had died out from such cases, and consequently such purely deformed and disabled cases were designated as "Burnt-outs." But, this conception of the mutilating stage of leprosy seems to have received a challenge from sceptics, in consequence of which it was decided by the conference to drop out of use the term "Burnt-out," and substitute for it "Disease arrested with deformities." Our knowledge of the actual mechanism of causation of these deformities and trophic ulcers and absorptive bone lesions, is still incomplete. We appear quite satisfied when it is explained that they are essentially " trophic " in nature; but we do not know how these trophic lesions are actually produced. Is it not possible that besides the trophic factor there is some other factor that helps to produce these lesions?

One frequently sees a sickening recurrence of trophic ulcers in the same limb or in another limb, even in cases that had received appropriate surgical treatment for their previous ulcers with immediately satisfactory results; and it is very difficult to explain why in some cases there should be a progressive involvement of the matatarsals or meta-carpals. necessitating repeated operations. Two cases with exactly similar ulcers are operated upon, and the necrosed bone or 
bones removed, and they heal up. One of these returns sooner or later with a recurring ulcer in the same limb. Injury to the periosteum covering the adjacent bones, during the previous operation, or constant pressure exercised on the devitalised limb while walking or performing any other natural act, may explain such recurrence. But these alone do not explain why there should be a recurrence after a long interval and a progressive involvement of, say, one metatarsal after another, even involving a bone so distantly situated as not to have been injured by a previous operative procedure. Are we to understand that the separate bundles of trophic fibres for the several bones in a limb tend to be affected in succession?

Muir 1933 (1) has recently advanced a very rational hypothesis to explain the production of early neural lesions of the cutis and subcutis in which the familiar acid fast bacillis of Hansen is either not seen or is very scarce. Is it unreasonable to suppose that the same neurotropic (or neurophilic as Muir prefers to term it) virus form of M. leprae which causes the primary neural lesions, may persist in the affected nerves or other tissues, and take a share in the actual production of the trophic lesions?

That this supposition is not altogether untenable will become evident when one considers the fact that similar trophic lesions appear either as a terminal event in many highly advanced cutaneous cases who have naturally or by appropriate treatment come down the curve of the disease, or even while they are still on the top of the curve in the C3 stage. A study of the C3-N3 cases, shows that while one part of the body is teeming with millions of bacilli (acid-fast) in nodules and infiltrated areas, another part of the body, say, a foot, shows a typical perforating ulcer. It is hard to believe that the familiar acid-fast bacillus can or does cause two entirely different types of lesions at the same time in the same case, even after allowing a broad margin for the natural differences in the structure of the skin and the nerves; and their respective powers of showing a cellular response to the presence of a foreign invader. Our credulity is still further taxed, when we find that purely neural cases with no acid-fast bacilli detected in any lesion previously, begin to show them when they pass on to the cutaneous stage, and we are told that these acid-fast bacilli were probably lying dormant somewhere in the system prior to their appearance in the newly formed cutaneous type of lesions. Gass and Rishi. (1934) (2) have produced evidence to the contrary, 
by their failure to find a single acid fast bacillus in the bonemarrow of purely neural type of cases. If the reticuloendothelial system is the stronghold of the bacilli as is supposed, then why are they not detected in the bone-marrow which forms an integral part of the R.E. System, in the purely neural cases? No significant difference in the trophic lesions shown by a purely $\mathrm{N} 3$ case and that shown by a C3$\mathrm{N} 3$ case, is noticed, so far as the lesions are concerned. How can one then explain that the paucity of bacilli in the nerves of the former and the abundance of bacilli in those of the latter, can both cause the same type of trophic lesions?

On the other hand, it would be perfectly rational to explain the appearance of the acid-fast bacilli in the neural cases passing on to the cutaneous type (N1-C1 cases) by supposing that these bacilli represent the modified or resistant forms of the hypothetical neurotropic virus form of $M$. leprae. And the appearance of trophic lesions in highly active advanced cutaneous cases with myriads of acidfast bacilli all over the body, can also be explained by the supposition that the neurotropic virus form is concerned with the trophic lesions as well as the earlier primary neural lesions, while the acid-fast form is associated with the leprotic (cutaneous) type of lesions. This tentative explanation is further strengthened by the following observations(a) No acid-fast bacilli have so far been found in the affected nerves in the earlier stages, whereas when the same nerves begin to react, a few acid-fast bacilli can be seen in smears taken from the sheaths of such nerves (b) purely neural lesions like anaesthetic or hypopigmented areas with no acidfast bacilli detected in them, when passing on to the cutaneous stage, begin to show a few acid-fast bacilli (c) in the so-called tuberculoid type of cases with well marked erythematous granular and raised lesions, sometimes all over the body, even as many as ten clips from ten such lesions have been examined without finding a single acid-fast bacillus in any one smear.

These observations lead one to believe that the familiar acid-fast bacillus, is probably not the primary form, but that it is a modified or resistant form of some other (ultramicroscopic?) organism, as yet undetected. The assumption of acid-fast characteristics, as well as the secretion of "gloea" to bind the bacilli into masses, may all represent defensive attempts on the part of the bacilli to withstand the onslaught of the phylactic powers of the body, and may be analogous to the formation of cysts by entamoeba hystolytica when the medium becomes unfavourable. 
In this connection, it may be germane to recollect that there are still some sceptics who deny that the acid-fast bacillus is the caustive organism of leprosy. The absence or extreme scarcity of the acid-fast bacilli in purely neural lesions in the earlier stages and in the "tuberculoid " type of cases, furnishes the " raison-d'etre" for such denial. Further, even the familiar acid-fast bacilli have so far resisted all attempts at cultivation " in vitro," and clinical experience testifies to their extreme pleomorphism. Thus, it is not uncommon to find in a smear taken from the nodule of an untreated C3 case, uniformly stained rods, beaded and curved or straight rods, and a group of coccoids all in the same field or in different fields. Hoffman 1933 (3) has given an excellent description of these different forms in which the acid-fast bacillus may be present and has suggested that the granular forms might represent either resistant or degenerating forms, and the coccoids might be analogous to spores, or they may be an evolutionary phase of a still smaller ultramicroscopic organism. Denney 1934 (4) has also described the extreme pleomorphism characteristic of the Hansen's bacillus. The view that the granular and coccoid forms are signs of degeneration, is no longer adhered to by several experienced workers. Similarly, the opinion that these differences are due to varying staining techniques, is also no longer tenable, because even with the same technique in the same smear, taken from an untreated case, such pleomorphic forms are encountered. Similarly even in cases which are clinically observed to be rapidly advancing and show no signs of retrogression, such pleomorphic forms of M. leprae are found. This shows that the acid-fast bacillary form is very probably a stage in the life-history of the virus of leprosy, and that it is by no means the primary stage.

Unless we postulate the existence of a virus form of the organism, it appears to me impossible satisfactorily to explain the occurrence of (a) relapses in cases that were purely neural and were rendered symptom-free by prolonged and adequate treatment; (b) the successive occurrence of trophic bone lesions in some cases in whom no acid-fast bacilli have ever been found; (c) the absence or extreme scantiness of acid-fast bacilli in well-marked " tuberculoid "type of cases; (d) the occurrence of trophic bone lesions in C3 cases while they are still on the top of the curve, with myriads of acidfast bacilli, and in $\mathrm{C} 2$ and $\mathrm{C} 1$ cases with comparative paucity of the same acid-fast bacilli, there being no significant difference in the trophic bone lesions shown by either the 
purely neural (N3) cases, or the highly advanced cutaneous and neural ( $\mathrm{C} 3-\mathrm{N} 3$ cases) and the moderate and mild cutaneous and secondarily neural $(\mathrm{C} 2-\mathrm{N} 3$ and $\mathrm{C} 1-\mathrm{N} 3$ cases); (e) the occurrence of relapses in the so called "Disease arrested with deformities" type of cases, after a fairly long interval, after their disease wa's declared arrested, by a competent worker, and during which interval there was no reasonable chance of at least some of them getting reinfected or developing a reinfection.

\section{Material For Study.}

In 1931, four of the so called "burnt-out" cases of leprosy, had to undergo an amputation of one of their legs for septic foot. A few months after amputation, though they appeared to be in good general health they all showed active signs of leprosy with new lesions, and one of them became a $\mathrm{Cl}$ case also. This was recorded by the present writer's colleague, Roy (1932) (5). The occurrence of these relapses served to disturb our complacent attitude towards these so-called "burnt-out" cases, and the present writer thought it necessary to examine them carefully with a view to detecting further cases of relapse. Twenty-six cases showing a reactivation of the disease were detected, and of these 20 were selected as definite cases of relapse, after a careful enquiry into their clinical histories, and after studying their previous charts very carefully. While considering this subject the belief that a non acid-fast form could alone exlain these relapses was strengthened.. Although these relapses were detected and studied in 1932, the publication of the findings was delayed on account of the fact that Dr. Muir; who was very much interested, took biopsy material from all the lesions with a view to comparing their histopathological features with those of the primary lesions. Dr. Muir has put forward the hypothesis that a neurophilic form of M. leprae may be present, and similarly Hoffman (Idem) has also suggested that such unrecognised forms may exist.

\section{CAUSES OF RELAPSE.}

All the relevant particulars regarding the relapsed cases are given in the table appended. It will be noticed that in most of the cases, septic feet or hands necessitating operations, with a fairly long stay in the hospital, both for the septic condition as well as for the associated illnesses, was the main predisposing factor. Excepting two males and two females, all the rest showed neural lesions such as new hypopigmented patches or hypopigmented and erythematous patches of the zone type. The two former showed cutaneous 
(leprotic) type of infiltrated lesions on the face or in the nose, from which acid-fast bacilli were found in fairly large numbers.

An analysis of the sex incidence of these cases brings out the interesting fact that thrice as many females have relapsed as males, their respective numbers being 15 and 5 . This shows that the naturally weaker sex have a greater tendency to relapse. Most of the females were past middle life and it is a point worth noting that they were very probably in the "climacteric" period when these relapses occurred. The metabolic disturbances incidental to this critical period in the life of women when superadded on to other minor ailments such as a short attack of malaria or a septic finger or toe, may probably induce relapses. On further analyzing the predisposing causes, we find that in one female they were multiple, " septic foot," " pregnancy and delivery," and "lactation," etc. In 12 out of 20 cases,

\begin{tabular}{|c|c|c|c|c|c|c|c|c|}
\hline 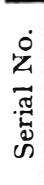 & Name. & $\begin{array}{l}\text { Sex \& } \\
\text { House } \\
\text { No. }\end{array}$ & $\begin{array}{l}\text { Declared } \\
\text { Disease } \\
\text { arrested } \\
\text { on }\end{array}$ & $\begin{array}{l}\text { Relapse } \\
\text { detected } \\
\text { on and the } \\
\text { type of } \\
\text { lesions } \\
\text { shown. }\end{array}$ & \multicolumn{2}{|c|}{$\begin{array}{l}\text { Interval } \\
\text { between } \\
\text { relapse } \\
\text { and } \\
\text { arrest } \\
\text { (Approx.) }\end{array}$} & $\begin{array}{l}\text { Causes of relapse as } \\
\text { ascertained from } \\
\text { Hospital charts and } \\
\text { Clinical History. }\end{array}$ & 禹 \\
\hline 1 & Abed Arjun & M 17 & $3 / 3 / 32$ & $5 / 5 / 32 \mathrm{~N}$ & $\begin{array}{c}\text { yrs. } \\
0\end{array}$ & $\begin{array}{l}\text { nths. } \\
2\end{array}$ & $\begin{array}{l}\text { Septic feet and gastric } \\
\text { complaints for } 3 \text { or } 4 \\
\text { months. }\end{array}$ & \\
\hline 2 & Lilu Lakhpati & M 7 & $5 / 3 / 31$ & $3 / 3 / 32 \mathrm{G}$ & 1 & 0 & $\begin{array}{l}\text { Dysentery Hook-worm } \\
\text { for about a month. }\end{array}$ & घี่ \\
\hline 3 & Behari Boaz ... & M 17 & $5 / 3 / 31$ & $3 / 3 / 32 \mathrm{G}$ & 1 & 0 & $\begin{array}{l}\text { Septic feet and Malaria } \\
\text { for a month. }\end{array}$ & 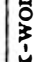 \\
\hline 4 & Jugal ... & M 24 & $22 / 11 / 30$ & $15 / 4 / 32 \mathrm{~N}$ & 1 & 4 & $\begin{array}{l}\text { Septic hand, bleeding } \\
\text { piles, dysentery and } \\
\text { hook-worm. }\end{array}$ & 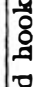 \\
\hline 5 & Kartik. & M 2 & $19 / 1 / 31$ & $15 / 2 / 32 \mathrm{~N}$ & 1 & 0 & Septic foot. & ב \\
\hline 6 & & & & & 1 & 3 & & \\
\hline 7 & & F 9 & & $15 / 3 / 32 \mathrm{~N}$ & 1 & 0 & Bronchitis. & ळ \\
\hline 8 & Sudha Sushila & F 10 & $12 / 3$ & $15 / 3 / 32 \mathrm{~N}$ & 1 & 0 & Mala & 8 \\
\hline 9 & Bila & F 14 & & $18 / 3 / 32 \mathrm{~N}$ & 1 & 3 & Sep & 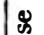 \\
\hline 10 & Sabi & F 18 & $29 / 11$ & $1 / 4 / 34 C_{1}$ & 1 & 4 & Mala & \\
\hline 11 & Gunabati & F 18 & 27 & $1 / 4 / 32 \mathrm{~N}$ & 1 & 4 & $\begin{array}{l}\text { leg (amputated) } \\
\text { Nephritis? }\end{array}$ & 崖 \\
\hline 12 & Monibala & $\begin{array}{ll}\text { F } & 19 \\
\text { F } & 19\end{array}$ & $25 / 11 / 30$ & $\begin{array}{l}5 / 4 / 32 \mathrm{~N} \\
5 / 4 / 32 \mathrm{~N}\end{array}$ & 1 & 4 & foot. & สี \\
\hline $\begin{array}{l}13 \\
14\end{array}$ & $\begin{array}{l}\text { Podda ... } \\
\text { Muchni }\end{array}$ & $\begin{array}{l}\text { F } 19 \\
\text { F } 20\end{array}$ & & $\begin{array}{l}5 / 4 / 32 \mathrm{~N} \\
5 / 4 / 32 \mathrm{~N}\end{array}$ & $\begin{array}{l}1 \\
1\end{array}$ & $\begin{array}{l}0 \\
4\end{array}$ & $\begin{array}{l}\text { Malaria. } \\
\text { Septic feet, pregnancy } \\
\text { delivery and lacta- }\end{array}$ & 范 \\
\hline 15 & Mukt & F 21 & & & 1 & 4 & $\begin{array}{l}\text { tion ? } \\
\text { Septic foot and Malaria. }\end{array}$ & \\
\hline 16 & & F 22 & & & 1 & 4 & $\begin{array}{l}\text { Prolonged fever and } \\
\text { diarrhoea. }\end{array}$ & \\
\hline 17 & Karuna Khenti & F 22 & $27 /$ & $32 \mathrm{~N}$ & 1 & 4 & Senility. & \\
\hline 18 & & F 24 & & & 1 & 4 & & \\
\hline 19 & Arun Bala $\quad \ldots$ & F 25 & & $9 / 4 / 32 \mathrm{~N}$ & 1 & 4 & Septic foot for 21 & \\
\hline 20 & Phulmani & F 25 & $25 / 11 / 30$ & $9 / 4 / 32 C_{1}$ & 1 & 4 & $\begin{array}{l}\text { Nothing could be ascer- } \\
\text { tained. }\end{array}$ & \\
\hline
\end{tabular}

M $=$ Male. $\quad \mathrm{F}=$ Female. $\quad \mathrm{Yr} .=$ Year. $\quad$ Mths. $=$ Months. $\mathrm{C}=$ Cutaneous. $\mathrm{N} \approx$ Neural. 
including the one female just mentioned above, septic feet or hands with or without other illnesses such as gastric disorders, nephritis, bronchitis, and malaria, were mainly responsible; while malaria (with hookworm probably) was definitely incriminated in three cases. Prolonged fever and diarrhoea was the cause in one case, malaria with-bronchitis was blamed in another, and dysentery or bleeding piles with septic hand and hookworm in a third; of the remaining two cases in which no definite predisposing cause could be ascertained, one could be reasonably attributed to senility. On the whole it is evident that some debilitating factor or factors, have been in operation for a fairly long time and they have caused the relapses.

\section{Discussion.}

Do these cases come under the category of relapses or re-infections? This is an important point for consideration. Except in one case in which the relapse occurred, two months after he was declared definitely "disease-arrested (with deformities)," in all the other cases the period that elapsed before the relapse was detected after they. were once definitely declared as "Disease-arrested with - deformities," varied from 1 year to 1 year and 4 months. This period falls short of the accepted minimum incubation period for leprosy, which is 2 years; and hence these cases cannot be considered a's "Re-infections," unless we are prepared to believe that the incubation period can be considerably shorter for re-infections in those who once have had the disease in any form, neural or cutaneous. If such re-infections are possible, then, considering the fact that we have about 300 cases or so, of the " disease arrested with deformities " type, most of whom suffer now and then from trophic disturbances of the feet or hands, living side by side with cutaneous (open) cases, the incidence of re-infection should be almost universal in them. On the contrary, a study of the leprolinresponse of the "disease-arrested with deformities" type of cases, using both the leprolins (Hansen's and Stefansky's) and carrying out the readings strictly according to Muir's technique (Muir (1933) (6), has shown that they have a fairly strong acquired resistance to Hansen's bacillus, and therefore cannot be considered to have got any special susceptibility to re-infection. That very few cases should have occurred under the conditions outlined just before, is itself a point in favour of these cases being relapses.

Of the 20 cases of relapse, only four showed the acid-fast bacilli in their new lesions, while the rest (16), showed chiefly 
neural type of lesions which were negative to acid-fast bacilli even on repeated examinations. It cannot be denied that the causative organisms of leprosy in whatever form and however few they might be, are present in such neural lesions. The very fact that we cannot find them in the familiar acidfast form, even on repeated examinations, shows that they exist in such lesions in a hitherto unrecognised form, and it is suggested that it is a neurotropic virus form. And the finding of the bacilli in four other cases of relapse that showed a few cutaneous type of lesions, indicates that there is a definite relationship between the unrecognised neurotropic virus form and the familiar acid-fast form, the latter very probably representing a resistant form of the former, the assumption of the acid-fast characteristic being a defensive attempt on the part of the virus. With regard to the habitat of the virus in these cases, it is possible that it might have been lying dormant in the affected nerves, lymphatics and in other parts of the reticulo-endothelial system.

\section{ConClusions.}

(1) The probable existence of a hitherto unrecognised non-acidfast neurotropic virus form of $M$. leprae is deduced from a consideration of :-

(a) the absence of the acid-fast bacilli in neural lesions as well as in the affected nerves in the earlier stages; (b) the presence of the same in reacting nerves and in neural lesions passing on to the cutaneous type $(\mathrm{N}-\mathrm{G})$; (c) the absence of the acid-fast bacilli or their extreme scantiness in the so-called "tuberculoid" type of lesions; (d) the occurrence of trophic lesions in purely neural cases (secondary neural cases N3) as well as in cutaneous cases of varying degrees while they are on the upward trend of the curve or when they are descending the curve of the disease, in the former, with no acid-fast bacilli or very few of them, confined to re-acting nerves; and in the latter, with abundant acid-fast bacilli (c) the recurrence of trophic bone lesions, after long intervals involving distantly situated bones.

(2) The virus form probably persists even in the "Diseasearrested with deformities" type of cases for a pretty long time, and can cause relapse of active signs with a reactivation of the disease, when the general health is sufficiently lowered by some debilitating factors, operating for a fairly long time.

\section{REFERENCES.}

1. Muir, E. (1933). "Leprous Nerve Lesions of the Cutis and Subcutis." International Journal of Leprosy, Vol. 1, No. 2, April, 1933.

2. Gass, H. H., and Rishi, D. P. (1934). "Examination of Bone-marrow for M. leprae." Leprosy in India, Vol. VI, No. 1, January, 1934.

3. Hoffman, W. H. (1933). "The Granular Forms of the Leprosy Bacillus." International Journal of Leprosy, Vol. 1, No. 2, April, 1933.

4. Denney, O. E. (1934). "A Microscopic Study of M. leprae." International Journal of Leprosy, Vol. II, No. 3.

5. Roy, A. (1932). "Relapse of Active signs in Burnt-out cases of Leprosy." Indian Medical Gazette, January, 1932, Vol. LXVII, No. 1.

6. Muir, E. (1933). "The Intradermal Leprolin Test." Leprosy in India, October, 1933, Vol. V, No. 4. 